\title{
A Review on Natural Fiber Reinforced Polymer Composite and Its Applications
}

\author{
Layth Mohammed, ${ }^{1}$ M. N. M. Ansari, ${ }^{1}$ Grace Pua, \\ Mohammad Jawaid, ${ }^{2}$ and M. Saiful Islam ${ }^{3}$ \\ ${ }^{1}$ Centre for Advance Materials, Department of Mechanical Engineering, Universiti Tenaga Nasional, 43000 Kajang, Selangor, Malaysia \\ ${ }^{2}$ Laboratory of Biocomposite Technology, Institute of Tropical Forestry and Forest Products (INTROP), \\ Universiti Putra Malaysia (UPM), 43400 Serdang, Selangor, Malaysia \\ ${ }^{3}$ Department of Chemistry, Faculty of Science, Universiti Putra Malaysia (UPM), 43400 Serdang, Selangor, Malaysia
}

Correspondence should be addressed to M. N. M. Ansari; ansari@uniten.edu.my

Received 18 February 2015; Revised 29 June 2015; Accepted 30 August 2015

Academic Editor: Adriana Kovalcik

Copyright (C) 2015 Layth Mohammed et al. This is an open access article distributed under the Creative Commons Attribution License, which permits unrestricted use, distribution, and reproduction in any medium, provided the original work is properly cited.

Natural fibers are getting attention from researchers and academician to utilize in polymer composites due to their ecofriendly nature and sustainability. The aim of this review article is to provide a comprehensive review of the foremost appropriate as well as widely used natural fiber reinforced polymer composites (NFPCs) and their applications. In addition, it presents summary of various surface treatments applied to natural fibers and their effect on NFPCs properties. The properties of NFPCs vary with fiber type and fiber source as well as fiber structure. The effects of various chemical treatments on the mechanical and thermal properties of natural fibers reinforcements thermosetting and thermoplastics composites were studied. A number of drawbacks of NFPCs like higher water absorption, inferior fire resistance, and lower mechanical properties limited its applications. Impacts of chemical treatment on the water absorption, tribology, viscoelastic behavior, relaxation behavior, energy absorption flames retardancy, and biodegradability properties of NFPCs were also highlighted. The applications of NFPCs in automobile and construction industry and other applications are demonstrated. It concluded that chemical treatment of the natural fiber improved adhesion between the fiber surface and the polymer matrix which ultimately enhanced physicomechanical and thermochemical properties of the NFPCs.

\section{Introduction}

The increase in environmental consciousness and community interest, the new environmental regulations and unsustainable consumption of petroleum, led to thinking of the use of environmentally friendly materials. Natural fiber is considered one of the environmentally friendly materials which have good properties compared to synthetic fiber [1].

A late current industry research identified that the worldwide natural fiber reinforced polymer composites industry sector reached U\$2.1 billion in 2010. Current pointers are that interest in NFPCs industry will keep on growing quickly around the world. The utilization of NFPCs has expanded considerably in the shopper merchandise as developing industry sectors throughout the last few years. As indicated by evaluations, over 5 years (2011-2016), the NFPCs industry is estimated to grow $10 \%$ worldwide [2].
Natural fibers in simple definition are fibers that are not synthetic or manmade. They can be sourced from plants or animals [3]. The use of natural fiber from both resources, renewable and nonrenewable such as oil palm, sisal, flax, and jute to produce composite materials, gained considerable attention in the last decades, so far. The plants, which produce cellulose fibers can be classified into bast fibers (jute, flax, ramie, hemp, and kenaf), seed fibers (cotton, coir, and kapok), leaf fibers (sisal, pineapple, and abaca), grass and reed fibers (rice, corn, and wheat), and core fibers (hemp, kenaf, and jute) as well as all other kinds (wood and roots) [4]. The most common and commercially natural fibers in the world and world production have been shown in Table 1.

Fiber reinforced polymer matrix got considerable attention in numerous applications because of the good properties and superior advantages of natural fiber over synthetic fibers in term of its relatively low weight, low cost, less 
TABLE 1: Natural fibers in the world and their world production [4].

\begin{tabular}{lc}
\hline Fiber source & World production $\left(10^{3}\right.$ ton $)$ \\
\hline Bamboo & 30.000 \\
Sugar cane bagasse & 75.000 \\
Jute & 2300 \\
Kenaf & 970 \\
Flax & 830 \\
Grass & 700 \\
Sisal & 375 \\
Hemp & 214 \\
Coir & 100 \\
Ramie & 100 \\
Abaca & 70 \\
\hline
\end{tabular}

damage to processing equipment, good relative mechanical properties such as tensile modulus and flexural modulus, improved surface finish of molded parts composite, renewable resources, being abundant [5], flexibility during processing, biodegradability, and minimal health hazards. NFPCs with a high specific stiffness and strength can be produced by adding the tough and light-weight natural fiber into polymer (thermoplastic and thermoset) [6]. On the other hand, natural fibers are not free from problems and they have notable deficits in properties. The natural fibers structure consists of (cellulose, hemicelluloses, lignin, pectin, and waxy substances) and permits moisture absorption from the surroundings which causes weak bindings between the fiber and polymer. Furthermore, the couplings between natural fiber and polymer are considered a challenge because the chemical structures of both fibers and matrix are various. These reasons for ineffectual stress transfer during the interface of the produced composites. Accordingly, natural fiber modifications using specific treatments are certainly necessary. These modifications are generally centered on the utilization of reagent functional groups which have ability for responding of the fiber structures and changing their composition. As a result, fiber modifications cause reduction of moisture absorption of the natural fibers which lead to an excellent enhancement incompatibility between the fiber and polymer matrix [7].

The wide applications of NFPCs are growing rapidly in numerous engineering fields. The different kinds of natural fibers reinforced polymer composite have received a great importance in different automotive applications by many automotive companies such as German auto companies (BMW, Audi Group, Ford, Opel, Volkswagen, Daimler Chrysler, and Mercedes), Proton company (Malaysian national carmaker), and Cambridge industry (an auto industry in USA). Beside the auto industry, the applications of natural fiber composites have also been found in building and construction industry, sports, aerospace, and others, for example, panels, window frame, decking, and bicycle frame [8].

In a review of chemical treatments of natural fibers, Kabir and coworkers [9] concurred that treatment is an important factor that has to be considered when processing natural fibers. They observed that fibers loose hydroxyl groups due to different chemical treatments, thereby reducing the hydrophilic behavior of the fibers and causing enhancement in mechanical strength as well as dimensional stability of natural fiber reinforced polymer composites. Their general conclusion was that chemical treatment of natural fibers results in a remarkable improvement of the NFPCs.

\section{Natural Fiber Reinforced Composites (NFPCs)}

Natural fiber polymer composites (NFPC) are a composite material consisting of a polymer matrix embedded with high-strength natural fibers, like jute, oil palm, sisal, kenaf, and flax [10]. Usually, polymers can be categorized into two categories, thermoplastics and thermosets. The structure of thermoplastic matrix materials consists of one or two dimensional moleculars, so these polymers have a tendency to make softer at an raised heat range and roll back their properties throughout cooling. On the other hand, thermosets polymer can be defined as highly cross-linked polymers which cured using only heat, or using heat and pressure, and/or light irradiation. This structure gives to thermoset polymer good properties such as high flexibility for tailoring desired ultimate properties, great strength, and modulus $[3,4]$. Thermoplastics widely used for biofibers are polyethylene [11], polypropylene (PP) [12], and poly vinyly chloride (PVC); hereas phenolic, polyester, and epoxy resins are mostly utilized thermosetting matrices [10]. Different factors can affect the characteristics and performance of NFPCs. The hydrophilic nature of the natural fiber [5] and the fiber loading also have impacts on the composite properties [13]. Usually, high fiber loading is needed to attain good properties of NFPCs [14]. Generally, notice that the rise in fiber content causes improving in the tensile properties of the composites [8]. Another vital factor that considerably impacts the properties and surface characteristics of the composites is the process parameters utilized. For that reason, appropriate process techniques and parameters should be rigorously chosen in order to get the best characteristics of producing composite [10]. The chemical composition of natural fibers also has a big effect on the characteristics of the composite represented by the percentage of cellulose, hemicellulose, lignin, and waxes. Table 2 shows the chemical composition of some common natural fibers [4].

Many researchers [8, 11, 15-17] have examined and researched the suitability, competitiveness, and capabilities of natural fibers embedded in polymeric matrices. The researchers $[4,18,19]$ concentrated on the effect of the fiber surface modifications as well as manufacturing processes in improving fiber/polymer compatibility. On the other hand, some researchers studied and compared between different natural fiber composites and their stability in various applications [20]. Al-Oqla and Sapuan [20] investigated the properties of jute/plastic composites such as crystallinity, fiber modification, thermal stability, weathering resistance, durability, in addition to their suitability to the automotive industry throughout ecodesign components. while Mohanty et al. [21] studied the effects of jute fiber on the mechanical properties 
TABLE 2: Chemical composition of some common natural fibers [4].

\begin{tabular}{|c|c|c|c|c|}
\hline Fiber & Cellulose (wt\%) & Hemicellulose (wt\%) & Ligning (wt\%) & Waxes (wt\%) \\
\hline Bagasse & 55.2 & 16.8 & 25.3 & - \\
\hline Bamboo & $26-43$ & 30 & $21-31$ & - \\
\hline Flax & 71 & $18.6-20.6$ & 2.2 & 1.5 \\
\hline Kenaf & 72 & 20.3 & 9 & - \\
\hline Jute & $61-71$ & $14-20$ & $12-13$ & 0.5 \\
\hline Hemp & 68 & 15 & 10 & 0.8 \\
\hline Ramie & $68.6-76.2$ & $13-16$ & $0.6-0.7$ & 0.3 \\
\hline Abaca & $56-63$ & $20-25$ & $7-9$ & 3 \\
\hline Sisal & 65 & 12 & 9.9 & 2 \\
\hline Coir & $32-43$ & $0.15-0.25$ & $40-45$ & \\
\hline Oil palm & 65 & - & 29 & - \\
\hline Pineapple & 81 & - & 12.7 & - \\
\hline Curaua & 73.6 & 9.9 & 7.5 & - \\
\hline Wheat straw & $38-45$ & $15-31$ & $12-20$ & - \\
\hline Rice husk & $35-45$ & $19-25$ & 20 & - \\
\hline Rice straw & $41-57$ & 33 & 8-19 & $8-38$ \\
\hline
\end{tabular}

of pure biodegradable polymer (Biopol), the mechanical properties of the resulted composites, impact strength, tensile strength, and bending strength, showed an increase when compared with pure Biopol. The tensile strength of jute Biopol was enhanced by $50 \%$, while bending strength and impact strength of the composites were enhanced by $30 \%$ and $90 \%$ in comparison to pure Biopol.

\section{General Characteristics of NFPCs}

The properties of natural fiber composite are different to each other according to previous studies, because of different kinds of fibers, sources, and moisture conditions. The performance of NFPCs relies on some factors, like mechanical composition, microfibrillar angle [20], structure [10], defects [22], cell dimensions [23], physical properties [4], chemical properties [24], and also the interaction of a fiber with the matrix [25]. Since every product in market has drawbacks, similarly, natural fiber reinforced polymer composites also have drawbacks. The couplings between natural fiber and polymer matrix are problem taken into consideration, as a result of the difference in chemical structure between these two phases. This leads to ineffective stress transfer during the interface of the NFPCs. Thus, the chemical treatments for the natural fiber are necessary to achieve good interface properties. The reagent functional groups in the chemical treatments have ability to react on the fiber structures and alter the fiber composition [9]. Natural fibers include a functional group named as hydroxyl group which makes the fibers hydrophilic. During manufacturing of NFPCs, weaker interfacial bonding occurs between hydrophilic natural fibre and hydrophobic polymer matrices due to hydroxyl group in natural fibres. This could produce NFPCs with weak mechanical and physical properties [8].

3.1. Mechanical Properties of the NFPCs. There are considerable enhancement and suggestions for the natural fibers that can be implemented in order to enhance their mechanical properties resulting in high strength and structure. Once the base structures are made strong, the polymers can be easily strengthened and improved [26]. There are number of aspects that effects of composite are performance level or activities, of which to name a few are the following;

(a) orientation of fiber [5],

(b) strength of fibers [8],

(c) physical properties of fibers [27],

(d) interfacial adhesion property of fibers [28] and many more.

NFPCs are such composites whose mechanical efficiency is dependent upon the interface provided by fiber-matrix along with the stress transfer function in which stress is transferred to fiber from matrix. This has been reported by many investigators in several researches $[1,23,29]$. Characteristic components of natural fibers such as orientation [30], moisture absorption [31], impurities [32], physical properties [33], and volume fraction [34] are such features that play a constitutive role in the determination of NFPCs mechanical properties. Mechanical properties of PLA, epoxy, PP, and polyester matrices can be affected by many types of natural fibers and to show some of them, Figure 1 is included.

NFPCs show even better mechanical properties than a pure matrix in cases where jute fibers are added in PLA (polylactic-acid); in this case, $75.8 \%$ of PLA's tensile strength was improved; however, introduction or incorporation of flax fibers showed a negative impact on this addition. The addition of flax fibers resulted in $16 \%$ reduced tensile strength of the composites. Conversely, composites of PP were improved with the incorporation of hemp, kenaf, and cotton [5]. By far, maximum improvement is only seen in such composites where jute or polyester has been incorporated where a total of $121 \%$ improvement is evident compared to pure polyester [5]. 
TABLE 3: Physicomechanical properties of natural fibers [38].

\begin{tabular}{lcccc}
\hline Fiber & Density $\left(\mathrm{g} / \mathrm{cm}^{3}\right)$ & Tensile strength $(\mathrm{MPa})$ & Young's modulus $(\mathrm{GPa})$ & Elongation at break $(\%)$ \\
\hline OPEFB & $0.7-1.55$ & 248 & 3.2 & 2.5 \\
Flax & 1.4 & $88-1500$ & $60-80$ & $1.2-1.6$ \\
Hemp & 1.48 & $550-900$ & 70 & 1.6 \\
Jute & 1.46 & $400-800$ & $10-30$ & 1.8 \\
Ramie & 1.5 & 500 & 44 & 2 \\
Coir & 1.25 & 220 & 6 & $15-25$ \\
Sisal & 1.33 & $600-700$ & 38 & - \\
Abaca & 1.5 & 980 & - & $3-10$ \\
Cotton & 1.51 & 400 & - & $2.7-6.9$ \\
Kenaf (bast) & 1.2 & 295 & - & - \\
Kenaf (core) & 0.21 & - & $19.7-27.1$ & 1.1 \\
Bagasse & 1.2 & $20-290$ & - & $3-4.7$ \\
Henequen & 1.4 & $430-580$ & 82 & $1-3$ \\
pineapple & 1.5 & $170-1672$ & 33.8 & 53 \\
Banana & 1.35 & 355 & & \\
\hline
\end{tabular}

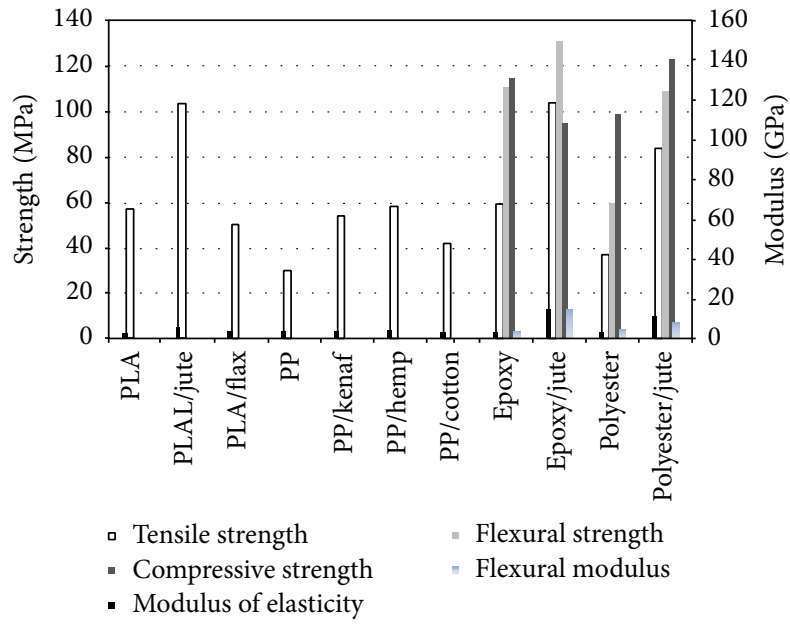

FIGURE 1: Some of mechanical properties of natural fiber reinforced polymer composite [5].

However, due to the rubber phase present in gum compound, a greater range of flexibility is present in such materials which results in reduced stiffness and storage modulus.

It is also known that stiffness and stress transfer in composites increases with an increased or excessive addition of fiber which provides a better loss modulus and also a better storage modulus. The loss modulus is also considered to be increased with fiber addition up to $756 \mathrm{MPa}$ at $50 \mathrm{phr}$ fiber loading compared to the loss modulus of gum that is $415 \mathrm{MPa}$ [8].

A group of researchers led by Ismail et al. [37] studied the effect of size and filler content on fiber characteristics that cures a wound or any part of the body. Along with this, mechanical properties of Oil Palm Wood Flour (OPWF) was also examined which is reinforced with (ENR) epoxidized natural rubber composites. When the fiber content is increased, torque of the fibers is also increased and with smallest possible particle size of OPWF, highest torque was noticed. However, increasing the factor of OPWF in ENR compounds showed reduced tensile strength and while reaching the break point a considerable elongation is evident. It also evident increase in elongation, tear strength, tensile modulus and hardness due to higher loading of OPWF. A higher tensile strength and tear strength as tensile modulus were identified in composites that were filled with even smallest proportion of OPWF [10]. The fracture behavior of composites is also affected due to the nonlinear mechanical behavior of natural fibers, under the influence of tensileshear loads [1]. Table 3 shows the mechanical properties for common types of natural fiber in the world [38].

The bonding strength between fiber and polymer matrix in the composite is consider a major factor in order to get superior fiber reinforcement composites properties. Because of pendant hydroxyl and polar groups in fiber, this leads to extremely high moisture absorption of fiber, resulting in weak interfacial bonding between the fiber and the hydrophobic matrix polymers. To develop composites with good mechanical properties, chemical modification of fibre carried out to reduce the hydrophilic behavior of fibers and the absorption of moisture [15, 39].

The different surface treatments of advanced composites applications were reviewed by several researchers [40-42]. The effects of different chemical treatments on cellulosic fibers that were employed as reinforcements for thermoplastics and thermoset were also examined. For the treatments, the different kinds of chemical treatment include silane [43], alkali [44], acrylation [45], benzoylation [46], maleated coupling agents [47], permanganate [48], acrylonitrile and acetylation grafting [49], stearic acid [50], peroxide [51], isocyanate [52], triazine [53], fatty acid derivate (oleoyl chloride), sodium chloride, and fungal [9]. The main purpose of surface treatments of natural fibers to enhanced fibre/matrix interfacial bonding and stress transferability of the composites.

The impact of alkaline treatment on surface properties of Iranian cultivated natural fibers was studied by 
Cordeiroa et al. [54]. The research revealed that alkaline treatment gets rid of some chemical components on the surface of the fibers, comprising uranic acid (hemicellulose), aromatic moieties (extractives), and nonpolar molecules from the partial lignin depolymerisation. There is a stronger effect on chemical components of nonwood fibers. Improving the crystallinity of nonwood fibers, in the softwood fibers result in only a minor increase. Hence, alkaline treatment can result in a remarkable improvement in the specific interaction of the fibers as well as improving the fibers' wettability.

Le Troedec et al. [55] revealed the effects of some chemical treatments, comprising ethylenediaminetetraacetic acid (EDTA), $\mathrm{NaOH}$, polyethylene imine (PEI), $\mathrm{CaCl}_{2}$, and $\mathrm{Ca}(\mathrm{OH})_{2}$. The effects were on the mechanical properties of the composite materials from mixtures of hemp fiber and lime by differential thermal evaluation and tests. The observation was that every treatment had a direct effect on the fiber surface. The treatment was with $6 \% \mathrm{NaOH}$ and led to cleaning fibers by removing the amorphous compounds, and the increase of the crystallinity index of fiber bundles, while the EDTA treatment led to separates fibers and complex calcium ions related to pectins. In brief, PEI treatment shows all studied properties an intermediate character and lime water treatment depicts calcium ions' fixation at the surface of fibers in comparison to a calcium chloride treatment which does not.

May-Pat et al. [1] reported on the impact of the interphase properties from well controlled surface treatment in the case of natural fibers. The fracture behavior and the mechanical properties of a NFPC depend on the properties of constituents and region of the fiber surface, or interphase, where the stress transfer occurs. Furthermore, the tailoring of the interphase by different kinds of surface treatments and carefully characterizing it provides a better knowledge of the behavior of the NFPCs. Moreover, different fiber surface treatments modify the natural fiber microstructure specifically under high loading rates.

Venkateshwaran et al. [35] studied the effect of alkali $(\mathrm{NaOH})$ treatments of various concentrations $(0.5 \%, 1 \%$, $2 \%, 5 \%, 10 \%, 15 \%$, and $20 \%$ ) on the mechanical properties of banana/epoxy composite. The results reported that as compared to other treated and untreated fiber composites, $1 \%$ $\mathrm{NaOH}$ treated fiber reinforced composites have a better properties. The alkali concentration on the fiber surfaces results in better mechanical properties of the resulted composite. However, the rising of alkali concentration maybe causes fiber surface damage, leading to a decrease of mechanical properties. The effect of different chemical treatment on the mechanical properties and characteristic of sisal-oil palm hybrid fiber reinforced natural rubber composites have been studied by John et al. [56]. With chemical treatment, the torque values increased which lead to greater crosslinking. Similarly, alkali treatment showed a rise in the composites' tensile strength in comparison to untreated composites and with $4 \% \mathrm{NaOH}$ treated fibers, optimum tensile strength was seen for resulted composites. In contrast, for composites treated with $4 \% \mathrm{NaOH}$ a strong interface is apparent because of a more superior adhesion between rubber and fiber is present which avoids solvent entry and a little swelling occurs.
Van de Weyenberg et al. [24] examined the impact of flax processing parameters, and the fiber treatment, on the mechanical properties of flax fiber reinforced epoxy composites. It was discovered that the employment of long flax slivers may not necessarily lead to more superior composite properties. The highest enhancement of the flexural properties of the flax fiber reinforced epoxy composites can be gotten by chemical treatments. There was an increase of transverse strength of up to $250 \%$ and transverse modulus, of up to $500 \%$. In addition, the longitudinal properties of the UD composites (both modulus and strength) showed improvements with $40 \%$ or more.

Some modifications in the chemical and physical properties of the lignocellulosic fibers can be observed after the treatment of the fiber of rubber wood with laccase enzymes. These chemical treatments lead to the amorphous lignin content, changing the hemicellulose content and ultimately the natural crystallinity [57]. The fiber has treatment effect on morphological and single fiber tensile strength of EFB fiber. The EFB fiber treated with boiling water, $2 \%$ sodium hydroxide $(\mathrm{NaOH})$, and mixing of boiling water and $\mathrm{NaOH}$ was examined by Norul Izani et al. [13]. It was revealed that it changed the properties of the fiber surface topography after the treatment. Compared to untreated EFB fiber, the treated EFB fibers with the two types of treatment were more thermal stability. On the other hand, the tensile strength and Young's modulus of the treated fiber showed a rise in comparison to untreated fibers. For tensile modulus, the alkaline treatment has enhanced the tensile properties of sugar palm fiber reinforced epoxy composites at better soaking times and concentrations of alkaline. On the other hand, the increase the alkaline concentration may lead to fiber damage [58].

Acrylonitrile Butadiene Styrene (ABS) with the coating effect of OPEFB fibers was tested BT. The coated process enhanced the mechanical and physical properties and also improved the fiber performance. The ABS treatment led to reducing the water absorption and also decreased the biodegradation potential of the fiber in contact with soil. With the coating, the tensile strength and elasticity moduli of the OPEFB fibers became better than what they were in the past. The surface area between fiber and soil particles increased by coating fiber, which led to improving the shear strength parameters of the fiber reinforced soils [66].

3.2. Flame Retardant Properties of the NFPCs. Due to ecofriendly and sustainability nature, natural fiber composites prefers as compared to conventional synthetic fibre based composites. They are applied in diversified domains $[9,18,20$, $38,67]$ such as building materials [68], aerospace industry, and automotive industry [69]. Natural fibers and polymers are organic materials and are very sensitive to alter any features if flame is introduced to them. Flame retardancy is another aspect that has become greatly significant in order to fulfill safety measures taken while developing natural fiber composites.

In the presence of flame, burning of composites takes place in five different steps as shown below:

(a) Heating. 
(b) Decomposition.

(c) Ignition.

(d) Combustion.

(e) Propagation [70].

If flame retardancy has been achieved in the aforementioned steps, no matter whether ignition step has been conducted or not, the procedure will be terminated before an actual ignition is set up. There are two forms of products that are obtained upon burning of composites; these two include high cellulose content and high lignin content. High cellulose provides chances of higher flammability whereas higher values of lignin show there is a greater chance of char formation [71]. Thermal resistance is provided by flax fibers [72]; however, silica or ash is another important feature that is helpful in extinguishing fire [73].

In order to enhance fire resistance of various NFPCs, different procedures are undertaken. Fire barriers are kind of barriers that can be applied to phenolics, ceramics, intumescents, glass mats, silicone, ablatives, and chemical additives too. Coatings and additives used in the system of intumescent are found to be very promising fire barrier treatments in which these barriers are expanded upon heating resulting in a cellular surface that is charred even. However, with the help of this charred surface, internal or underlying components and protected against flux and heat.

One of the well-known or profound flame retardants for reinforced polymers (natural fibers) is used with the combination of char developing cellulose material [74]. The only method of reducing combustion in this scenario is through increasing stability and char formation in the polymer. This will result in reduced flammability, decrease visible smoke, and restrict the volume of products produced due to combustions [72]. Fire retardant coating is another method that helps in enhancement of fire resistance property of composites. This coating is done at the end or finishing stage or impregnation. Due to changes in the fibers and lingocellulosic particles, fire resistance is altered during the process of manufacturing [75].

The two most widely used metal hydroxide flame retardants are known to be aluminum hydroxide $\left[\mathrm{Al}\left(\mathrm{OH}_{3}\right)\right]$ and magnesium hydroxide $\left[\mathrm{Mg}(\mathrm{OH})_{2}\right]$ which are purposefully added to polymers. The chemical reaction through which these two flame retardants decompose are as follows:

$$
\begin{gathered}
2 \mathrm{Al}(\mathrm{OH})_{3} \longrightarrow \mathrm{Al}_{2} \mathrm{O}_{3}+3 \mathrm{H}_{2} \mathrm{O} \quad \Delta H=20 \mathrm{cal} / \mathrm{g} \\
\mathrm{Mg}(\mathrm{OH})_{2} \longrightarrow \mathrm{MgO}+\mathrm{H}_{2} \mathrm{O} \quad \Delta H=328 \mathrm{cal} / \mathrm{g}
\end{gathered}
$$

Out of these two flame retardants, magnesium hydroxide display better thermal stability as compared to aluminum hydroxide since the temperature range given off by the decomposition of magnesium hydroxide is nearly 300-320 degrees centigrade $\left({ }^{\circ} \mathrm{C}\right)$ which is much higher than the temperature range offered by aluminum hydroxide that is only $200^{\circ} \mathrm{C}$. For this reason, aluminum hydroxide is not considered to be thermally stable as it cannot be used for polyamides, polypropylene, or others whereas magnesium hydroxide can be used.
It was also shown in a research that the addition of expandable graphite (EG) and ammonium polyphosphate (APP) in composite polymer as a source of flame retardant (FR) helps in enhancing flax fiber reinforced PP composite's property of fire retardancy. It was also shown that heat release rate (HRR) in a composite additive of $30 \mathrm{wt} \%$ of flax fiber and $25 \mathrm{wt} \%$ of EG (expandable graphite) was decreased to 35 from $167 \mathrm{~kW} / \mathrm{m}^{2}$ [76].

Spirocyclic pentaerythritol bisphosphorate disphosphoryl melamine (SPDPM) is a type of intumescent flame retardant for PLA that was studied by Zhan et al. [77]. Char formation that is a result of spirocyclic pentaerythritol bisphosphorate disphosphoryl melamine (SPDPM), an active component of flame retardancy, enhances antidripping performance of PLA and flame retardancy too with an addition of $25 \mathrm{wt} \%$. Flame retardancy is not an easy thing to be imparted and it is only possible if there is an extensive high loading of inorganic filler.

Hapuarachchi and Peijs [78] studied the development of fully bio-based natural fiber composite that has enhanced features of fire or flame retardancy. This natural fiber composite was developed with the help of PLA polymers that were derived from crops accompanied with 2 kinds of nanofillers which are able to produce synergy corresponding to flame retardancy. Upon analysis, after incorporating hemp fiber mat in PLA resin, decrease in PHRR (peak heat release) in calorimeter will be shown.

3.3. Biodegradability of the NFPCs. High strength composites are resultant products of natural fiber reinforcement in polymers which also provide extra or improved biodegradability, low cost, light weight, and enhanced properties related to mechanical structure [29]. At temperatures as high as $240^{\circ} \mathrm{C}$, natural fibers start degrading whereas constituents of fiber, such as hemicelluloses, cellulose, lignin, and others, start degrading at different levels of temperature; for example, at $200^{\circ} \mathrm{C}$ lignin starts to decompose whereas at temperatures higher than this other constituents will also degrade [9].

Since thermal stability of the fibers is dependent on the structural constituents of fibers, it can be improved if the concentration levels or the structural constituents are completely removed, such as lignin and hemicelluloses. This can be achieved with the help of chemical treatments. Development of fibers and materials that provide services are two important aspects which should be considered while degradating natural fibers [9]. Natural fibers have a short lifetime with minimum environmental damage upon degradation whereas synthetic ones affect environment due to pollution caused by degradation. Lignin, hemicelluloses, and cellulose concentrations or composition affect thermal degradation features of lingo-cellulosic materials [13]. More than fifty percent weight of jute or Biopol composite is lost after exactly 1500 days of burial [21].

3.4. Energy Absorption of the NFPCs. High strength, energy absorption, and stiffness are obtained by composite materials which are widely used in automotive and motorsport sectors of industry mainly due to the property of mass reduction [79]. 
Enhanced energy absorption is evident from the increased volume fraction that is only possible in the presence of low speed such as $2.5 \mathrm{~m} / \mathrm{s}$ [80]. On the other hand, at high speeds, such as $300 \mathrm{~m} / \mathrm{s}$, similar performance is shown by flax, jute, and hemp, but jute showed brittleness and low strength of fibers [81]. Potential of NFPCs that is required for application in providing sustainable energy absorption was investigated by Meredith et al. While keeping focus on motorsport [80]. Vacuum Assisted Resin Transfer Molding (VARTM) technique is used to test conical specimens of flax, jute, and hemp for their properties and features. Various values exhibited by different kinds of materials were recorded to analyze specific energy absorption (SEA).

\subsection{Tribology Properties of NFPCs. Since every material} has some wear and friction properties that degrade with respect to time, the tribological loadings are important to consider for an improved mechanical part design [5]. Around $90 \%$ failure is obtained due to differences in tribological loading conditions which alters their wear and friction properties [82]. Reinforcement is a method with which fiber's or polymers tribological properties are altered (either positively or negatively) [83]. Studies on different kinds of tribological analysis have been conducted on fibers including kenaf/epoxy [84], betelnut fiber reinforced polyester [85], sisal/phenolic resin [86], sugarcane fiber reinforced polyester (SCRP) [87], and cotton/polyester [88]. Improvement in wear performance of PLA was evident due to the addition of natural fibers in which wear rate of composites was quite low in comparison to wear rate at higher loads on neat PLA [82].

Kenaf fibers reinforced with epoxy composite were used by Chin and Yousif [84] for a kind of bearing application, in which they showed an $85 \%$ enhancement of wear performance and normal orientation in composites. Wear and friction features of glass fiber/polyester (GRP) and sugarcane fiber/polyester (SCRP) were studied by El-Tayeb with different parameters including speed, the time taken for test, and load [87]. The research results concluded SCRP as a competitor of GRP composite. The same characteristics were studied by Xin et al. [86] for sisal fiber reinforced resin brake composites which showed sisal fiber can be used instead of asbestos in brake pads $[89,90]$.

Laminated composites were developed with the help of three different natural fibers such as grewia, nettle, optiva, and sisal. This connection of natural fibers was studied by Bajpai et al. in which a hot compression procedure was used to incorporate three different materials in a PLA polymer [82]. Friction and wear features of composites were examined under different situations such as dry contact condition with varying operating parameters. Due to an option of variable operating parameters, applied load was varied in between range of 10 to $30 \mathrm{~N}$ with a speed ranging from 1 to $3 \mathrm{~m} / \mathrm{s}$ and sliding distance of thousand to three thousand meters. The research results showed infusion of natural fiber mats, in PLA matrix, is capable of enhancing wear and frictional behavior of neat polymers. An approximate reduction of $10-44 \%$ in the coefficient of friction with a greater reduction of $70 \%$ seen in developed composites for specific wear rate is visualized in comparison to neat PLA [82].
3.6. Water Absorption Characteristics of the NFPCs. Natural fibers work well as reinforcement in polymers. However, the main weakness of the application of natural fibers is their susceptibility to moisture [91]. Mechanical properties of polymeric composites have a strong dependence on the interface adhesion between the fiber and the polymer matrix [15]. The natural fibers are rich of cellulose, hemicelluloses, lignin, and pectins, all of which are hydroxy 1 groups; that is, they are usually hydrophilic sources and strong polar whilst polymers show considerable hydrophobicity. Thus, there are major challenges of suitability between the matrix and fiber that weakens interface region between matrices and natural fibers [5]. At the composite materials' outer layers, water absorption happens and decreases gradually into the bulk of the matrix. A generally high water intake by composite materials results in an increased weight of wet profiles, a conceivable decline in their strength, and increment in their deflection, swelling, and causing pressure on nearby structures. These can cause warping, buckling, bigger possibility of their microbial inhabitation, freeze, and unfreeze caused destruction of mechanical characteristics of composite materials [92].

Oil palm fiber natural rubber (OPF-NR) composites increased in the water absorption percentage corresponding to an increase in fiber loading because of the fibers' hydrophilicity. The absorption behavior of NR showed modifications from Fickian to non-Fickian with additional OPF because of the microcracks and the viscoelastic nature of the polymer [8]. In the woven pandanus/banana fabric composites tests, woven pandanus fabric composites increased the water uptake compared to woven banana fabric composites because of higher lignin content and hemicellulose, as well as the presence of defects in the composite system [93]. Furthermore, temperature can affect the percentage of water absorption of the composites. At $65 \%$ humidity at $21^{\circ} \mathrm{C}$, the equilibrium moisture content of some natural fiber can be observed in Table 4 [4]. It was revealed that the water absorption of OPF-NR composite was less than of OPF-sisal fiber-NR hybrid biocomposite. The incorporation of sisal fiber that contains relatively more holocellulose (23\%), which is exceptionally hydrophilic brought on more water intake. Besides, the lignin content material of OPF (19\%) was bigger than sisal fiber (9\%). Lignin being hydrophobic reduces the water absorption [8].

Many researchers $[8,56]$ showed the effect of coupling agent such as maleic anhydride polyethylene and chemical treatments such as bleaching, acetylation, and alkali treatment on reduction moisture absorption of NFPCs. The surface of the fibers is cleaned during the chemical treatments to ensure there are no impurities which increases the fiber surface roughness and preventing the moisture absorption via the removal of the coat of $\mathrm{OH}$ groups of fiber as seen in equation below $[5,9]$ :

$$
\text { Fiber- } \mathrm{OH}+\mathrm{NaOH} \longrightarrow \text { Fiber- } \mathrm{O}^{-} \mathrm{Na}^{+}+\mathrm{H}_{2} \mathrm{O}
$$

Sreekala and Thomas [91] investigated the moisture absorption properties of OPEFB fiber in different temperature condition. They also studied the effect of different modification 
TABLE 4: The equilibrium moisture content of different natural fiber at $65 \%$ relative humidity $(\mathrm{RH})$ and $21^{\circ} \mathrm{C}[4]$.

\begin{tabular}{lc}
\hline Fiber & Equilibrium moisture content (\%) \\
\hline Sisal & 11 \\
Hemp & 9.0 \\
Jute & 12 \\
Flax & 7 \\
Abaca & 15 \\
Ramie & 9 \\
Pineapple & 13 \\
Coir & 10 \\
Bagasse & 8.8 \\
Bamboo & 8.9 \\
\hline
\end{tabular}

on OPEFB fiber, such as silane treatment, gamma irradiation, latex coating, mercerization, acetylation, peroxide treatment, and isocyanate treatment on moisture absorption properties. They concluded that all the treatment causes the seduction in moisture absorption properties in all temperatures.

The mercerization of OPF-sisal fiber-NR hybrid composites led to reducing water adsorption of the composite by improving the adhesive characteristics of fiber surface and also providing a large surface area which causes better mechanical interlocking [94]. Shinoj et al. [8] conducted the effect of chemical treatment for agave fibers on moisture adsorption before blending in a polymer matrix. The chemical treatment is achieved using four types of reagents, acetic anhydride (Ac), maleic anhydride (MA), styrene (S), and acrylic acid (AA). This paper concludes that the chemical treatment causes decrease in the global diffusivity of water and also concludes that the water mobility in the fiber core is more than at the surface.

3.7. Viscoelastic Behavior of the NFPCs. Dynamic mechanical measurements or the viscoelastic behavior over a range of temperatures provides valuable insight into the structure, morphology, and determination of the interface characteristics of natural fiber composite materials [95]. Storage modulus gives an insight into the load bearing capability and the stiffness behavior of natural fiber composite materials. Storage modulus is a measure of the maximum energy stored in the material during one cycle of oscillation. The mechanical damping coefficient is the ratio of the loss modulus to the storage modulus and is related to the degree of molecular mobility in the polymeric material. On the other hand, loss modulus is proportional to the amount of energy dissipated as heat by the sample [96].

The viscoelastic behavior of novel commingled biocomposites based on polypropylene/jute yarns is reported by [96]. By using commingling method, jute yarn reinforced polypropylene commingled composites were prepared. The viscoelastic behavior or dynamic mechanical properties of the result commingled composites were studied according to the fiber content and different kinds of chemical treatments such as potassium permanganate $\left(\mathrm{KMnO}_{4}\right)$, maleic anhydride modified polypropylene (MAPP), toluene diisocyanate

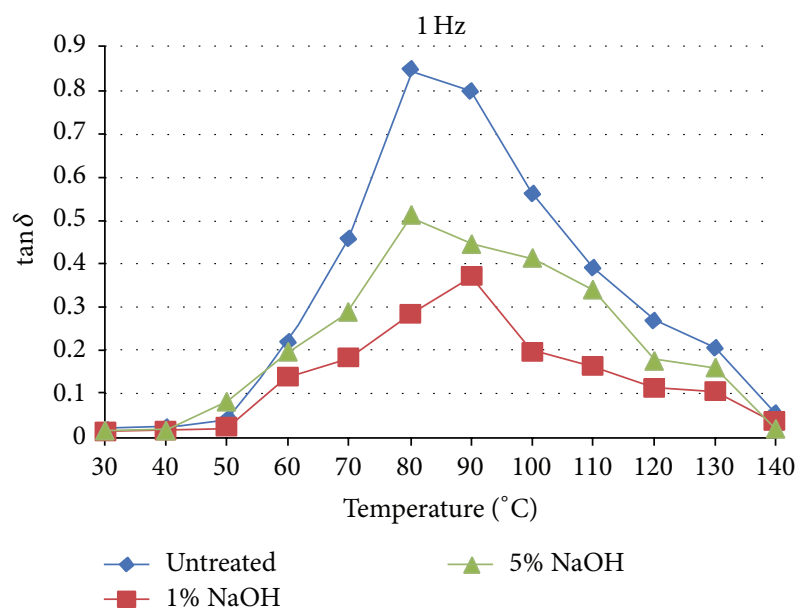

FIGURE 2: $\tan \delta$ versus temperature curves of the alkali treated and untreated composites at $1 \mathrm{~Hz}$ frequency [35].

(TDI), and stearic acid (ST). This study concluded that increasing of fiber content leads to increasing the storage and loss modulus of the composite. On the other hand, at all temperatures, the chemical treatment by $\mathrm{KMnO}_{4}$ and MAPP leads to increasing the storage modulus and loss modulus of the respective treated composites than the untreated ones.

By using the dynamic mechanical analyzer, Venkateshwaran et al. [35] studied the impact of alkali treatments on the viscoelastic behavior of natural fiber composite. The corresponding viscoelastic properties were determined as a function of temperature and frequency when the measurements were executed in the tensile mode of the used equipment. At the temperature range of $30-140^{\circ} \mathrm{C}$ at $0.1,1$, and $10 \mathrm{~Hz}$ frequencies, respectively, the experiments executed the graphs plotted, as storage modulus $\left(\mathrm{E}^{-}\right)$versus temperature and $\tan \delta$ versus temperature, as shown in Figures 2 and 3 [35].

3.8. Relaxation Behavior of the NFPCs. Natural fiber possesses an intrinsic relaxation behavior which has a main function in the stress relaxation of NFPCs. Thus, the tensile stress relaxation of the reinforcing fiber needs to be studied in detail [38]. Sreekala et al. [29], for instance, did such a study focusing on the character of individual OPEFB fiber and, in addition, examined the fiber surface modification effects, ageing, and strain level on the fiber relaxation behavior. The fibers stress relaxation was lessened significantly with surface treatments, like latex modification, and thus decreasing resulting physical interaction between the latex particles and fiber surface. Also, water and thermal ageing reduce the rate of relaxation for the oil palm fiber; the rate of stress relaxation of the OPEFB fiber was optimized at $10 \%$ strain level which is shown in Figure 4, while the relaxation modulus values for the fiber show similar trends as in the case of stress relaxation as shown in Figure 5. On the other hand, the stress relaxation rate of OPF-sisal fiber-NR hybrid composites showed a reduction with an increase in fiber percentage [97]. 


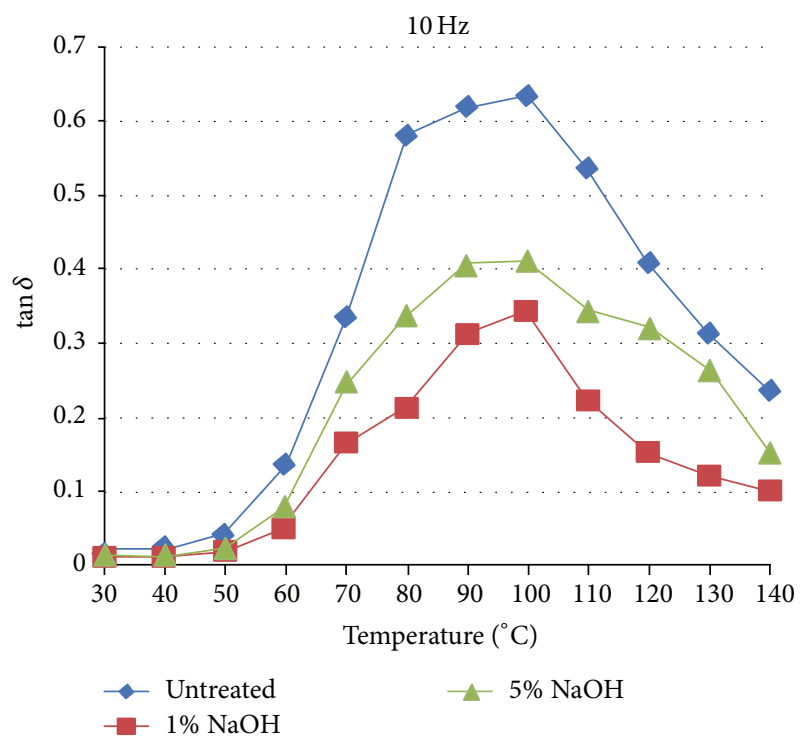

FIGURE 3: $\tan \delta$ versus temperature curves of alkali treated and untreated composites [35].

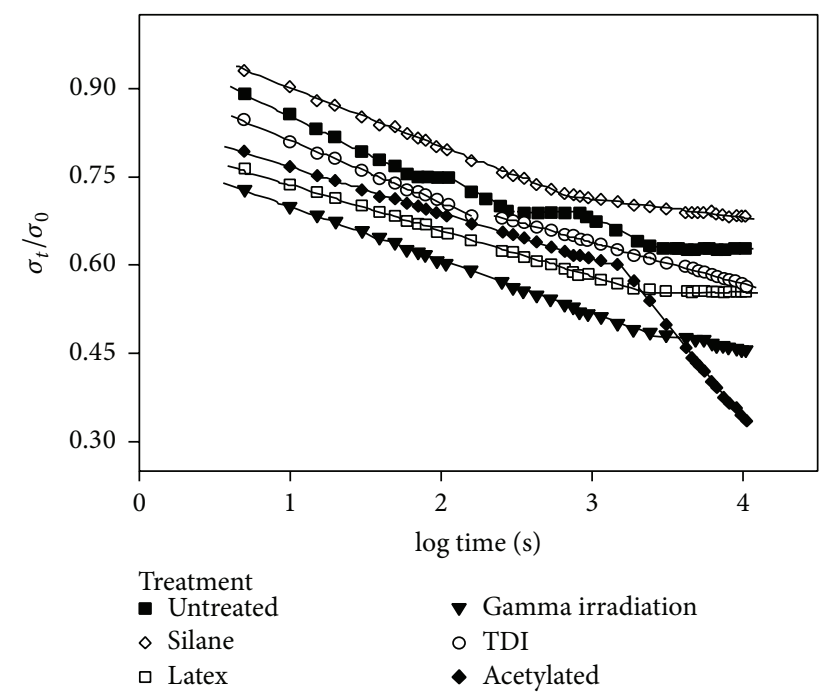

FIGURE 4: Stress relaxation curves of untreated and treated OPEFB fiber at $10 \%$ strain [29].

3.9. Thermal Properties of NFPCs. The untreated OPFs are thermally more stable when compared with treated ones, while OPF is considered thermally more stable compared to flax fibers and hemp fibers. Increase of temperatures from $20^{\circ} \mathrm{C}$ to $150^{\circ} \mathrm{C}$ causes increase of the heat capability of OPFs particularly from $1.083 \mathrm{Jg}^{-1}{ }^{\circ} \mathrm{C}^{-1}$ to $3.317 \mathrm{Jg}^{-1}{ }^{\circ} \mathrm{C}^{-1}$ [98]. The thermal diffusivity, thermal conductivity, and specific heat of the flax/HDPE composites lessened with a rise in fiber composition. However, the thermal conductivity and thermal diffusivity showed no significant changes in the range of $170-200^{\circ} \mathrm{C}$. The biocomposites' specific heat showed gradual increase with temperature [4]. By using polycarbonate to generate functional composites, pineapple leaf fiber was the support. The changed pineapple leaf fibers composite,

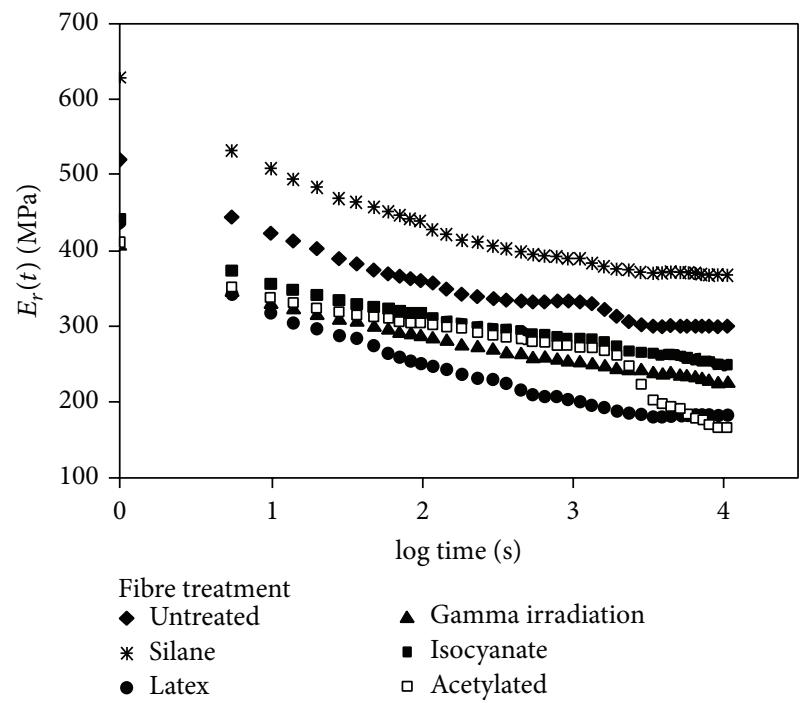

FIGURE 5: Relaxation modulus curves of untreated and treated OPEFB fiber at $10 \%$ strain [29].

treated with silane, showed the impact strengths and highest tensile. The composites' thermal stability is lower than the neat polycarbonate resin according to the thermogravimetric examination. Besides that, the thermal stability lessened with a rise in pineapple leaf fiber composition [4].

Enzymatic treatment for many natural fibers such as flax and hemp often natural fibers can lead to improvement in surface and thermal properties [56]. Hemicellulose and pectinase are the treatments which can improve the thermal properties of the fibers mentioned. The enzymes possess an attractive state for the improvement of the natural fibers' surfaces for natural fiber composite application [67].

Norul Izani et al. [13] studied the effect of chemical treatment on the morphological and tensile strength of the EFB fiber. The treatments were by the types of treatments, $2 \%$ sodium hydroxide $(\mathrm{NaOH})$ and combination of both $\mathrm{NaOH}$ and boiling water. The chemical treatment by $\mathrm{NaOH}$ led to enhancing the fiber surface topography, thermal stability, and tensile strength of the fiber, while the chemical treatment using $\mathrm{NaOH}$ and water boiling caused the higher thermal properties of the EFB fibers compared to untreated fibers.

\section{Natural Fiber Polymer Composites Application}

The applications of NFPCs are growing rapidly in numerous engineering fields. The different kinds of natural fibers such as jute, hemp, kenaf, oil palm, and bamboo reinforced polymer composite have received a great importance in different automotive applications, structural components, packing, and construction $[5,99]$. NFPCs are finding in electrical and electronic industries, aerospace, sports, recreation equipment, boats, machinery office products, and so forth. The widespread application of NFPCs in polymer composites due to its low specific weight, relatively high strength, relatively low production cost, resistance to corrosion and fatigue, 
TABLE 5: The application of natural fiber composites in automotive industry [59-62].

\begin{tabular}{|c|c|c|}
\hline Manufacturer & Model & Application \\
\hline Rover & 2000 and others & Rear storage shelf/panel, and insulations \\
\hline Opel & Vectra, Astra, Zafira & Door panels, pillar cover panel, head-liner panel, and instrumental panel \\
\hline Volkswagen & Passat Variant, Golf, A4, Bora & Seat back, door panel, boot-lid finish panel, and boot-liner \\
\hline Audi & $\begin{array}{l}\text { A2, A3, A4, A4 Avant, A6, A8, } \\
\text { Roadstar, Coupe }\end{array}$ & $\begin{array}{l}\text { Boot-liner, spare tire-lining, side and back door panel, seat back, and hat } \\
\text { rack }\end{array}$ \\
\hline Daimler Chrysler & $\begin{array}{l}\text { A, C, E, and S class, EvoBus } \\
\text { (exterior) }\end{array}$ & $\begin{array}{l}\text { Pillar cover panel, door panels, car windshield/car dashboard, and business } \\
\text { table }\end{array}$ \\
\hline BMW & 3,5 and 7 series and other Pilot & $\begin{array}{l}\text { Seat back, headliner panel, boot-lining, door panels, noise insulation } \\
\text { panels, and moulded foot well linings }\end{array}$ \\
\hline Peugeot & 406 & Front and rear door panels, seat backs, and parcel shelf \\
\hline Fiat & $\begin{array}{l}\text { Punto, Brava, Marea, Alfa Romeo } \\
\text { 146, 156, } 159\end{array}$ & Door panel \\
\hline General Motors & $\begin{array}{l}\text { Cadillac De Ville, Chevrolet Trail } \\
\text { Blazer }\end{array}$ & Seat backs, cargo area floor mat \\
\hline Toyota & ES3 & Pillar garnish and other interior parts \\
\hline Saturn & L300 & Package trays and door panel \\
\hline Volvo & V70, C70 & Seat padding, natural foams, and cargo floor tray \\
\hline Ford & Mondeo CD 162, Focus & Floor trays, door inserts, door panels, B-pillar, and boot-liner \\
\hline Saab & $9 \mathrm{~S}$ & Door panels \\
\hline Renault & Clio, Twingo & Rear parcel shelf \\
\hline Toyota & Raum, Brevis, Harrier, Celsior, & Floor mats, spare tire cover, door panels, and seat backs \\
\hline Mitsubishi & & Cargo area floor, door panels, and instrumental panel \\
\hline \multirow[t]{2}{*}{ Mercedes Benz } & $\mathrm{C}, \mathrm{S}, \mathrm{E}$, and A classes & $\begin{array}{l}\text { Door panels (flax/sisal/wood fibers with epoxy resin/UP matrix), glove box } \\
\text { (cotton fibers/wood molded, flax/sisal), instrument panel support, } \\
\text { insulation (cotton fiber), molding rod/apertures, seat backrest panel } \\
\text { (cotton fiber), trunk panel (cotton with PP/PET fibers), and seat } \\
\text { surface/backrest (coconut fiber/natural rubber) }\end{array}$ \\
\hline & Trucks & $\begin{array}{l}\text { Internal engine cover, engine insulation, sun visor, interior insulation, } \\
\text { bumper, wheel box, and roof cover }\end{array}$ \\
\hline Citroen & C5 & Interior door panelling \\
\hline Lotus & Eco Elise (July 2008) & Body panels, spoiler, seats, and interior carpets \\
\hline Rover & 2000 and others & Insulation, rear storage shelf/panel \\
\hline VAUXHALL & Corsa, Astra, Vectra, Zafira & $\begin{array}{l}\text { Headliner panel, interior door panels, pillar cover panel, and instrument } \\
\text { panel }\end{array}$ \\
\hline
\end{tabular}

totally biodegradable, improving the surface finish of molded part composites, relatively good mechanical properties, available and renewable sources as compared to synthetic fibers $[5,98]$. On the other hand, there is a physical disadvantage of the NFPCs such as moisture absorption, restricted processing temperature, and variable quality and this disadvantage led to limiting their performance [73].

4.1. Natural Fiber Composites Applications in the Interior Car. Most of the car companies in the world have done a lot of investigation in order to insert the NFPCs in their products. The car manufacture in Europe has done various researches to increase the applications of NFPCs in automotive industry, especially in car interior such as seat backs, parcel shelves, boot linens, front and rear door linens, truck linens, and door-trim panels [89]. Beside the use for car interior parts in automobile industry, natural fiber embedded in polymers has been used for high requirement applications for exterior auto body components, such as the middle section between the headlights above the fender of a passenger bus [18].

German auto companies (BMW, Audi Group, Ford, Opel, Volkswagen, Daimler Chrysler, and Mercedes) utilize the cellulose fibers composites in various automobile part, shown in Figure 6, such as using coco nut fibers rubber latex composites for the seats of the Mercedes Benz A-class model and using fax-sisal fiber mat reinforced epoxy door panels of Mercedes Benz E-class model [8]. Audi company uses flax/sisal mat reinforced polyurethane composite with a mix to make door trim panels [60]. Ford is using kenaf fibers imported from Bangladesh in their "Mondeo" model and the door panels of the Mondeo are manufactured from kenaf reinforced PP composites while using flax in floor trays [61]. Kenaf and flax mixture has gone into package trays and door panel inserts for Opel Vectras. Volkswagen company used 
TABLE 6: Natural fiber composite applications in industry [3, 63-65].

\begin{tabular}{|c|c|}
\hline Fiber & Application in building, construction, and others \\
\hline Hemp fiber & $\begin{array}{l}\text { Construction products, textiles, cordage, geotextiles, paper \& packaging, furniture, electrical, manufacture bank } \\
\text { notes, and manufacture of pipes }\end{array}$ \\
\hline Oil palm fiber & $\begin{array}{l}\text { Building materials such as windows, door frames, structural insulated panel building systems, siding, fencing, } \\
\text { roofing, decking, and other building materials [14] }\end{array}$ \\
\hline Wood fiber & Window frame, panels, door shutters, decking, railing systems, and fencing \\
\hline Flax fiber & $\begin{array}{l}\text { Window frame, panels, decking, railing systems, fencing, tennis racket, bicycle frame, fork, seat post, snowboarding, } \\
\text { and laptop cases }\end{array}$ \\
\hline Rice husk fiber & Building materials such as building panels, bricks, window frame, panels, decking, railing systems, and fencing \\
\hline Bagasse fiber & Window frame, panels, decking, railing systems, and fencing \\
\hline Sisal fiber & $\begin{array}{l}\text { In construction industry such as panels, doors, shutting plate, and roofing sheets; also, manufacturing of paper and } \\
\text { pulp }\end{array}$ \\
\hline Stalk fiber & Building panel, furniture panels, bricks, and constructing drains and pipelines \\
\hline Kenaf fiber & $\begin{array}{l}\text { Packing material, mobile cases, bags, insulations, clothing-grade cloth, soilless potting mixes, animal bedding, and } \\
\text { material that absorbs oil and liquids }\end{array}$ \\
\hline Cotton fiber & Furniture industry, textile and yarn, goods, and cordage \\
\hline Coir fibers & $\begin{array}{l}\text { Building panels, flush door shutters, roofing sheets, storage tank, packing material, helmets and postboxes, mirror } \\
\text { casing, paper weights, projector cover, voltage stabilizer cover, a filling material for the seat upholstery, brushes and } \\
\text { brooms, ropes and yarns for nets, bags, and mats, as well as padding for mattresses, seat cushions }\end{array}$ \\
\hline Ramie fiber & $\begin{array}{l}\text { Use in products as industrial sewing thread, packing materials, fishing nets, and filter cloths. It is also made into } \\
\text { fabrics for household furnishings (upholstery, canvas) and clothing, paper manufacture. }\end{array}$ \\
\hline Jute fiber & Building panels, roofing sheets, door frames, door shutters, transport, packaging, geotextiles, and chip boards. \\
\hline
\end{tabular}

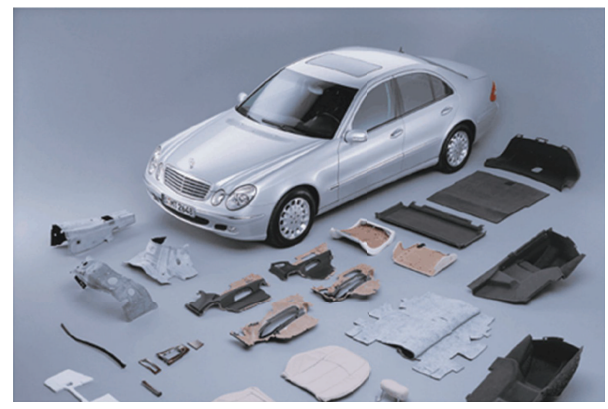

FIGURE 6: Automobile components made of natural fiber composites [36].

cellulose fiber to make Seatback, door panel, boot-lid finish panel, boot-liner in Passat Variant, Golf, A4, and Bora model.

BMW Group has a lot of NFPCs into its automobiles. BMW Group used about 10000 tonnes of natural fiber in 2004 [100]. Each BMW 7 series car boats $24 \mathrm{~kg}$ of renewable raw materials, with flax and sisal in the interior door lining panels. Also use cotton in the soundproofing, wool in the upholstery, and wood fiber in the seat back. Daimler-Benz in Germany is also working with a range of natural fibers \pm sisal, jute, coconut, European hemp, and flax \pm as reinforcing fibers in high-quality polypropylene components in order to replace glass fibers. Daimler-Benz has developed the dashboards and center armrest consoles along with seat shells and paneling on seat backs. Moreover, it increased the utilization of NFPCs in some automobiles by approximately $98 \%$ over earlier models by utilizing natural fibers, for example, abaca and flax. On the other hand, the Cambridge industry made rear shelf trim panels of the 2000 model Chevrolet Impala using flax fiber polypropylene composite $[8,101]$. Toyota, Proton, Volvo, and other automobile companies used cellulose fiber to make car parts as shown in Table 5.

4.2. The Natural Fiber Applications in the Industry. Other than the car industry, the applications of NFPCs are found in building and construction, aerospace, sports, and more, such as partition boards, ceilings, boats, office products, and machinery. The most applications of NFPCs are concentrated on nonload bearing indoor components in civil engineering because of their vulnerability to environmental attack [72]. Green buildings are wanted to be ecologically mindful, suitable, and healthy place to live and work. Biocomposites is consider one of the major materials utilized as a part of green materials at this time. It could be categorized, with regard to their application in the building market, into two principle products: firstly, structural biocomposites, which include bridge as well as roof structure, and secondly, nonstructural biocomposites which include window, exterior construction, composites panels, and door frame [2].

The wide advantages of natural fibers reinforced composites such as high stiffness to weight ratio, lightweight, and biodegradability give them suitability in different application in building industries [102]. Van de Weyenberg et al. [24] have shown that good properties of thin walled elements such as high strength in tension and compression, made of sisal fiber reinforced composite, give it a wide area of application, for instance, structural building members, permanent formwork, tanks, facades, long span roofing elements, and pipes strengthening of existing structures. On the other hand, 
bamboo fiber can be used in structural concrete elements as reinforcement, while sisal fiber and coir fiber composites have been used in roofing components in order to replace asbestos [15]. Natural fiber reinforced concretes products in construction applications like sheets (both plain and corrugated) and boards are light in weight and are ideal for use in roofing, ceiling, and walling for the construction of low cost houses [103]. Table 6 shows the various applications of cellulose fiber in industry, construction, and other industries.

\section{Conclusions}

Natural fiber reinforced polymer composites have beneficial properties such as low density, less expensive, and reduced solidity when compared to synthetic composite products, thus providing advantages for utilization in commercial applications (automotive industry, buildings, and constructions). Using natural fibers as reinforcement for polymeric composites introduces positive effect on the mechanical behavior of polymers. This paper evaluates the characteristics and properties of natural fiber reinforced polymer composites: mechanical, thermal, energy absorption, moisture absorption, biodegradability, flame retardancy, tribology properties. Viscoelastic behavior and relaxation behavior of NFPCs are researched. Also the application of NFPCs in automobile and industry is reported. The effects of chemical treatment of the natural fiber properties were also addressed. The physical and mechanical properties of these NFPCs can be further enhanced through the chemical treatment, while moisture absorption of the NFPCs can be reduced through surface modification of fibers such as alkalization and addition of coupling agents.

\section{Conflict of Interests}

The authors declare that there is no conflict of interests regarding the publication of this paper.

\section{References}

[1] A. May-Pat, A. Valadez-González, and P. J. Herrera-Franco, "Effect of fiber surface treatments on the essential work of fracture of HDPE-continuous henequen fiber-reinforced composites," Polymer Testing, vol. 32, no. 6, pp. 1114-1122, 2013.

[2] N. Uddin, Ed., Developments in Fiber-Reinforced Polymer (FRP) Composites for Civil Engineering, Elsevier, 2013.

[3] A. Ticoalu, T. Aravinthan, and F. Cardona, "A review of current development in natural fiber composites for structural and infrastructure applications," in Proceedings of the Southern Region Engineering Conference (SREC '10), pp. 113-117, Toowoomba, Australia, November 2010.

[4] O. Faruk, A. K. Bledzki, H.-P. Fink, and M. Sain, "Biocomposites reinforced with natural fibers: 2000-2010," Progress in Polymer Science, vol. 37, no. 11, pp. 1552-1596, 2012.

[5] A. Shalwan and B. F. Yousif, "In state of art: mechanical and tribological behaviour of polymeric composites based on natural fibres," Materials \& Design, vol. 48, pp. 14-24, 2013.

[6] Y. Xie, C. A. S. Hill, Z. Xiao, H. Militz, and C. Mai, "Silane coupling agents used for natural fiber/polymer composites: a review," Composites Part A: Applied Science and Manufacturing, vol. 41, no. 7, pp. 806-819, 2010.

[7] S. S. Ray and M. Bousmina, "Biodegradable polymers and their layered silicate nanocomposites: in greening the 21st century materials world," Progress in Materials Science, vol. 50, no. 8, pp. 962-1079, 2005.

[8] S. Shinoj, R. Visvanathan, S. Panigrahi, and M. Kochubabu, "Oil palm fiber (OPF) and its composites: a review," Industrial Crops and Products, vol. 33, no. 1, pp. 7-22, 2011.

[9] M. M. Kabir, H. Wang, K. T. Lau, and F. Cardona, "Chemical treatments on plant-based natural fibre reinforced polymer composites: an overview," Composites Part B: Engineering, vol. 43, no. 7, pp. 2883-2892, 2012.

[10] H. Ku, H. Wang, N. Pattarachaiyakoop, and M. Trada, "A review on the tensile properties of natural fiber reinforced polymer composites," Composites Part B: Engineering, vol. 42, no. 4, pp. 856-873, 2011.

[11] F. Z. Arrakhiz, M. El Achaby, M. Malha et al., "Mechanical and thermal properties of natural fibers reinforced polymer composites: doum/low density polyethylene," Materials \& Design, vol. 43, pp. 200-205, 2013.

[12] G. Di Bella, V. Fiore, G. Galtieri, C. Borsellino, and A. Valenza, "Effects of natural fibres reinforcement in lime plasters (kenaf and sisal vs. Polypropylene)," Construction and Building Materials, vol. 58, pp. 159-165, 2014.

[13] M. A. Norul Izani, M. T. Paridah, U. M. K. Anwar, M. Y. Mohd Nor, and P. S. H'Ng, "Effects of fiber treatment on morphology, tensile and thermogravimetric analysis of oil palm empty fruit bunches fibers," Composites Part B: Engineering, vol. 45, no. 1, pp. 1251-1257, 2013.

[14] I. S. M. A. Tawakkal, M. J. Cran, and S. W. Bigger, "Effect of kenaf fibre loading and thymol concentration on the mechanical and thermal properties of PLA/kenaf/thymol composites," Industrial Crops and Products, vol. 61, pp. 74-83, 2014.

[15] M. J. John and S. Thomas, "Biofibres and biocomposites," Carbohydrate Polymers, vol. 71, no. 3, pp. 343-364, 2008.

[16] E. Jayamani, S. Hamdan, M. R. Rahman, and M. K. B. Bakri, "Comparative study of dielectric properties of hybrid natural fiber composites," Procedia Engineering, vol. 97, pp. 536-544, 2014.

[17] C. C. Eng, N. A. Ibrahim, N. Zainuddin, H. Ariffin, and W. M. Z. W. Yunus, "Impact strength and flexural properties enhancement of methacrylate silane treated oil palm mesocarp fiber reinforced biodegradable hybrid composites," The Scientific World Journal, vol. 2014, Article ID 213180, 8 pages, 2014.

[18] N. Graupner, A. S. Herrmann, and J. Müssig, "Natural and man-made cellulose fibre-reinforced poly (lactic acid)(PLA) composites: an overview about mechanical characteristics and application areas," Composites Part A: Applied Science and Manufacturing, vol. 40, no. 6-7, pp. 810-821, 2009.

[19] K. Bocz, B. Szolnoki, A. Marosi, T. Tábi, M. Wladyka-Przybylak, and G. Marosi, "Flax fibre reinforced PLA/TPS biocomposites flame retarded with multifunctional additive system," Polymer Degradation and Stability, vol. 106, pp. 63-73, 2014.

[20] F. M. Al-Oqla and S. M. Sapuan, "Natural fiber reinforced polymer composites in industrial applications: feasibility of date palm fibers for sustainable automotive industry," Journal of Cleaner Production, vol. 66, pp. 347-354, 2014.

[21] A. K. Mohanty, M. A. Khan, and G. Hinrichsen, "Surface modification of jute and its influence on performance of biodegradable jute-fabric/Biopol composites," Composites Science and Technology, vol. 60, no. 7, pp. 1115-1124, 2000. 
[22] T. Hänninen, A. Thygesen, S. Mehmood, B. Madsen, and M. Hughes, "Mechanical processing of bast fibres: the occurrence of damage and its effect on fibre structure," Industrial Crops and Products, vol. 39, no. 1, pp. 7-11, 2012.

[23] V. K. Thakur and M. K. Thakur, "Processing and characterization of natural cellulose fibers/thermoset polymer composites," Carbohydrate Polymers, vol. 109, pp. 102-117, 2014.

[24] I. Van de Weyenberg, J. Ivens, A. De Coster, B. Kino, E. Baetens, and I. Verpoest, "Influence of processing and chemical treatment of flax fibres on their composites," Composites Science and Technology, vol. 63, no. 9, pp. 1241-1246, 2003.

[25] D. Dai and M. Fan, "Wood fibres as reinforcements in natural fibre composites: structure, properties, processing and applications," in Natural Fibre Composites: Materials, Processes and Properties, chapter 1, pp. 3-65, Woodhead Publishing, 2014.

[26] V. S. Srinivasan, S. R. Boopathy, D. Sangeetha, and B. V. Ramnath, "Evaluation of mechanical and thermal properties of banana-flax based natural fibre composite," Materials \& Design, vol. 60, pp. 620-627, 2014.

[27] J.-C. Bénézet, A. Stanojlovic-Davidovic, A. Bergeret, L. Ferry, and A. Crespy, "Mechanical and physical properties of expanded starch, reinforced by natural fibres," Industrial Crops and Products, vol. 37, no. 1, pp. 435-440, 2012.

[28] A. R. Kakroodi, S. Cheng, M. Sain, and A. Asiri, "Mechanical, thermal, and morphological properties of nanocomposites based on polyvinyl alcohol and cellulose nanofiber from Aloe vera rind," Journal of Nanomaterials, vol. 2014, Article ID 903498, 7 pages, 2014.

[29] M. S. Sreekala, M. G. Kumaran, and S. Thomas, "Stress relaxation behaviour in oil palm fibres," Materials Letters, vol. 50, no. 4, pp. 263-273, 2001.

[30] B. Ren, T. Mizue, K. Goda, and J. Noda, "Effects of fluctuation of fibre orientation on tensile properties of flax sliver-reinforced green composites," Composite Structures, vol. 94, no. 12, pp. 3457-3464, 2012.

[31] Y. Pan and Z. Zhong, "A micromechanical model for the mechanical degradation of natural fiber reinforced composites induced by moisture absorption," Mechanics of Materials, vol. 85, pp. 7-15, 2015.

[32] E. Jayamani, S. Hamdan, M. R. Rahman, and M. K. B. Bakri, "Investigation of fiber surface treatment on mechanical, acoustical and thermal properties of betelnut fiber polyester composites," Procedia Engineering, vol. 97, pp. 545-554, 2014.

[33] L. Boopathi, P. S. Sampath, and K. Mylsamy, "Investigation of physical, chemical and mechanical properties of raw and alkali treated Borassus fruit fiber," Composites Part B: Engineering, vol. 43, no. 8, pp. 3044-3052, 2012.

[34] M. Ramesh, T. S. A. Atreya, U. S. Aswin, H. Eashwar, and C. Deepa, "Processing and mechanical property evaluation of banana fiber reinforced polymer composites," Procedia Engineering, vol. 97, pp. 563-572, 2014.

[35] N. Venkateshwaran, A. Elaya Perumal, and D. Arunsundaranayagam, "Fiber surface treatment and its effect on mechanical and visco-elastic behaviour of banana/epoxy composite," Materials \& Design, vol. 47, pp. 151-159, 2013.

[36] S. N. Monteiro, K. G. Satyanarayana, A. S. Ferreira et al., "Selection of high strength natural fibers," Matéria, vol. 15, no. 4, pp. 488-505, 2010.

[37] H. Ismail, H. D. Rozman, R. M. Jaffri, and Z. A. Mohd Ishak, "Oil palm wood flour reinforced epoxidized natural rubber composites: the effect of filler content and size," European Polymer Journal, vol. 33, no. 10-12, pp. 1627-1632, 1997.
[38] M. Jawaid and H. P. S. Abdul Khalil, "Cellulosic/synthetic fibre reinforced polymer hybrid composites: a review," Carbohydrate Polymers, vol. 86, no. 1, pp. 1-18, 2011.

[39] M. George, P. G. Mussone, Z. Abboud, and D. C. Bressler, "Characterization of chemically and enzymatically treated hemp fibres using atomic force microscopy and spectroscopy," Applied Surface Science, vol. 314, pp. 1019-1025, 2014.

[40] P. Wongsriraksa, K. Togashi, A. Nakai, and H. Hamada, "Continuous natural fiber reinforced thermoplastic composites by fiber surface modification," Advances in Mechanical Engineering, vol. 5, Article ID 685104, 2013.

[41] J. Gassan and A. K. Bledzki, "Possibilities for improving the mechanical properties of jute/epoxy composites by alkali treatment of fibres," Composites Science and Technology, vol. 59, no. 9, pp. 1303-1309, 1999.

[42] M. Z. Rong, M. Q. Zhang, Y. Liu, G. C. Yang, and H. M. Zeng, "The effect of fiber treatment on the mechanical properties of unidirectional sisal-reinforced epoxy composites," Composites Science and Technology, vol. 61, no. 10, pp. 1437-1447, 2001.

[43] T. P. T. Tran, J.-C. Bénézet, and A. Bergeret, "Rice and Einkorn wheat husks reinforced poly(lactic acid) (PLA) biocomposites: effects of alkaline and silane surface treatments of husks," Industrial Crops and Products, vol. 58, pp. 111-124, 2014.

[44] S. I. Hossain, M. Hasan, M. N. Hasan, and A. Hassan, "Effect of chemical treatment on physical, mechanical and thermal properties of ladies finger natural fiber," Advances in Materials Science and Engineering, vol. 2013, Article ID 824274, 6 pages, 2013.

[45] A. O’Donnell, M. A. Dweib, and R. P. Wool, "Natural fiber composites with plant oil-based resin," Composites Science and Technology, vol. 64, no. 9, pp. 1135-1145, 2004.

[46] H. Luo, G. Xiong, C. Ma et al., "Mechanical and thermomechanical behaviors of sizing-treated corn fiber/polylactide composites," Polymer Testing, vol. 39, pp. 45-52, 2014.

[47] H. Ismail, A. Rusli, and A. A. Rashid, "Maleated natural rubber as a coupling agent for paper sludge filled natural rubber composites," Polymer Testing, vol. 24, no. 7, pp. 856-862, 2005.

[48] A. Paul, K. Joseph, and S. Thomas, "Effect of surface treatments on the electrical properties of low-density polyethylene composites reinforced with short sisal fibers," Composites Science and Technology, vol. 57, no. 1, pp. 67-79, 1997.

[49] F. Corrales, F. Vilaseca, M. Llop, J. Gironès, J. A. Méndez, and P. Mutjè, "Chemical modification of jute fibers for the production of green-composites," Journal of Hazardous Materials, vol. 144, no. 3, pp. 730-735, 2007.

[50] F. G. Torres and M. L. Cubillas, "Study of the interfacial properties of natural fibre reinforced polyethylene," Polymer Testing, vol. 24, no. 6, pp. 694-698, 2005.

[51] A. Hidayat and S. Tachibana, "Characterization of polylactic acid (PLA)/kenaf composite degradation by immobilized mycelia of Pleurotus ostreatus," International Biodeterioration \& Biodegradation, vol. 71, pp. 50-54, 2012.

[52] L. He, X. Li, W. Li, J. Yuan, and H. Zhou, "A method for determining reactive hydroxyl groups in natural fibers: application to ramie fiber and its modification," Carbohydrate Research, vol. 348, pp. 95-98, 2012.

[53] K. Xie, H. Liu, and X. Wang, "Surface modification of cellulose with triazine derivative to improve printability with reactive dyes," Carbohydrate Polymers, vol. 78, no. 3, pp. 538-542, 2009.

[54] N. Cordeiroa, M. Ornelasa, A. Ashorib, S. Sheshmanic, and H. Norouzic, "Investigation on the surface properties of chemically 
modified natural fibers using inverse gas chromatography," Carbohydrate Polymers, vol. 87, no. 4, pp. 2367-2375, 2012.

[55] M. Le Troedec, D. Sedan, C. Peyratout et al., "Influence of various chemical treatments on the composition and structure of hemp fibres," Composites Part A: Applied Science and Manufacturing, vol. 39, no. 3, pp. 514-522, 2008.

[56] M. J. John, B. Francis, K. T. Varughese, and S. Thomas, "Effect of chemical modification on properties of hybrid fiber biocomposites,' Composites Part A: Applied Science and Manufacturing, vol. 39, no. 2, pp. 352-363, 2008.

[57] M. Nasir, A. Gupta, M. D. H. Beg, G. K. Chua, and A. Kumar, "Fabrication of medium density fibreboard from enzyme treated rubber wood (Hevea brasiliensis) fibre and modified organosolv lignin," International Journal of Adhesion and Adhesives, vol. 44, pp. 99-104, 2013.

[58] M. Rokbi, H. Osmani, A. Imad, and N. Benseddiq, "Effect of chemical treatment on flexure properties of natural fiberreinforced polyester composite," Procedia Engineering, vol. 10, pp. 2092-2097, 2011.

[59] H. L. Bos, The potential offlax fibres as reinforcement for composite materials [Ph.D. thesis], Technische Universiteit Eindhoven, Eindhoven, The Netherlands, 2004.

[60] B. C. Suddell, "Industrial fibres: recent and current developments," in Proceedings of the Symposium on Natural Fibres, vol. 20, pp. 71-82, FAO, CFC, Rome, Italy, October 2008.

[61] K. Pickering, Ed., Properties and Performance of Natural-Fibre Composites, Woodhead Publishing, Cambridge, UK, 2008.

[62] A. K. Mohanty, M. Misra, and L. T. Drzal, Eds., Natural Fibers, Biopolymers, and Biocomposites, Taylor \& Francis, 2005.

[63] T. Sen and H. N. Reddy, "Various industrial applications of hemp, kinaf, flax and ramie natural fibres," International Journal of Innovation, Management and Technology, vol. 2, pp. 192-198, 2011.

[64] U. S. Bongarde and V. D. Shinde, "Review on natural fiber reinforcement polymer composite," International Journal of Engineering Science and Innovative Technology, vol. 3, no. 2, pp. 431-436, 2014.

[65] L. Mwaikambo, "Review of the history, properties and application of plant fibres," African Journal of Science and Technology, vol. 7, no. 2, p. 121, 2006.

[66] F. Bateni, F. Ahmad, A. S. Yahya, and M. Azmi, "Performance of oil palm empty fruit bunch fibres coated with acrylonitrile butadiene styrene," Construction and Building Materials, vol. 25, no. 4, pp. 1824-1829, 2011.

[67] M. George, P. G. Mussone, and D. C. Bressler, "Surface and thermal characterization of natural fibres treated with enzymes," Industrial Crops and Products, vol. 53, pp. 365-373, 2014.

[68] K. Joseph, R. D. T. Filho, B. James, S. Thomas, and L. H. de Carvalho, "A review on sisal fiber reinforced polymer composites," Revista Brasileira de Engenharia Agrícola e Ambiental, vol. 3, no. 3, pp. 367-379, 1999.

[69] C. Alves, P. M. C. Ferrão, A. J. Silva et al., "Ecodesign of automotive components making use of natural jute fiber composites," Journal of Cleaner Production, vol. 18, no. 4, pp. 313-327, 2010.

[70] M. Sain, S. H. Park, F. Suhara, and S. Law, "Flame retardant and mechanical properties of natural fibre-PP composites containing magnesium hydroxide," Polymer Degradation and Stability, vol. 83, no. 2, pp. 363-367, 2004.

[71] A. Alhuthali, I. M. Low, and C. Dong, "Characterisation of the water absorption, mechanical and thermal properties of recycled cellulose fibre reinforced vinyl-ester eco-nanocomposites,"
Composites Part B: Engineering, vol. 43, no. 7, pp. 2772-2781, 2012.

[72] Z. N. Azwa, B. F. Yousif, A. C. Manalo, and W. Karunasena, "A review on the degradability of polymeric composites based on natural fibres," Materials \& Design, vol. 47, pp. 424-442, 2013.

[73] E. Gallo, B. Schartel, D. Acierno, F. Cimino, and P. Russo, "Tailoring the flame retardant and mechanical performances of natural fiber-reinforced biopolymer by multi-component laminate," Composites Part B: Engineering, vol. 44, no. 1, pp. 112119, 2013.

[74] S. Fatima and A. R. Mohanty, "Acoustical and fire-retardant properties of jute composite materials," Applied Acoustics, vol. 72, no. 2-3, pp. 108-114, 2011.

[75] N. P. G. Suardana, M. S. Ku, and J. K. Lim, "Effects of diammonium phosphate on the flammability and mechanical properties of bio-composites," Materials \& Design, vol. 32, no. 4, pp. 1990-1999, 2011.

[76] B. Schartel, U. Braun, U. Knoll et al., "Mechanical, thermal, and fire behavior of bisphenol a polycarbonate/multiwall carbon nanotube nanocomposites," Polymer Engineering \& Science, vol. 48, no. 1, pp. 149-158, 2008.

[77] J. Zhan, L. Song, S. Nie, and Y. Hu, "Combustion properties and thermal degradation behavior of polylactide with an effective intumescent flame retardant," Polymer Degradation and Stability, vol. 94, no. 3, pp. 291-296, 2009.

[78] T. D. Hapuarachchi and T. Peijs, "Multiwalled carbon nanotubes and sepiolite nanoclays as flame retardants for polylactide and its natural fibre reinforced composites," Composites Part A: Applied Science and Manufacturing, vol. 41, no. 8, pp. 954-963, 2010.

[79] G. Savage, "Development of penetration resistance in the survival cell of a Formula 1 racing car," Engineering Failure Analysis, vol. 17, no. 1, pp. 116-127, 2010.

[80] J. Meredith, R. Ebsworth, S. R. Coles, B. M. Wood, and K. Kirwan, "Natural fibre composite energy absorption structures," Composites Science and Technology, vol. 72, no. 2, pp. 211-217, 2012.

[81] P. Wambua, B. Vangrimde, S. Lomov, and I. Verpoest, "The response of natural fibre composites to ballistic impact by fragment simulating projectiles," Composite Structures, vol. 77, no. 2, pp. 232-240, 2007.

[82] P. K. Bajpai, I. Singh, and J. Madaan, "Tribological behavior of natural fiber reinforced PLA composites," Wear, vol. 297, no. 1-2, pp. 829-840, 2013.

[83] N. S. M. El-Tayeb, B. F. Yousif, and T. C. Yap, “Tribological studies of polyester reinforced with CSM 450-R-glass fiber sliding against smooth stainless steel counterface," Wear, vol. 261, no. 3-4, pp. 443-452, 2006.

[84] C. W. Chin and B. F. Yousif, "Potential of kenaf fibres as reinforcement for tribological applications," Wear, vol. 267, no. 9-10, pp. 1550-1557, 2009.

[85] U. Nirmal, B. F. Yousif, D. Rilling, and P. V. Brevern, "Effect of betelnut fibres treatment and contact conditions on adhesive wear and frictional performance of polyester composites," Wear, vol. 268, no. 11-12, pp. 1354-1370, 2010.

[86] X. Xin, C. G. Xu, and L. F. Qing, "Friction properties of sisal fibre reinforced resin brake composites," Wear, vol. 262, no. 5-6, pp. 736-741, 2007.

[87] N. S. M. El-Tayeb, "A study on the potential of sugarcane fibers/polyester composite for tribological applications," Wear, vol. 265, no. 1-2, pp. 223-235, 2008. 
[88] S. A. R. Hashmi, U. K. Dwivedi, and N. Chand, "Graphite modified cotton fibre reinforced polyester composites under sliding wear conditions," Wear, vol. 262, no. 11-12, pp. 1426-1432, 2007.

[89] M. M. Davoodi, S. M. Sapuan, D. Ahmad, A. Aidy, A. Khalina, and M. Jonoobi, "Concept selection of car bumper beam with developed hybrid bio-composite material," Materials \& Design, vol. 32, no. 10, pp. 4857-4865, 2011.

[90] N. Banthia and R. Gupta, "Influence of polypropylene fiber geometry on plastic shrinkage cracking in concrete," Cement and Concrete Research, vol. 36, no. 7, pp. 1263-1267, 2006.

[91] M. S. Sreekala and S. Thomas, "Effect of fibre surface modification on water-sorption characteristics of oil palm fibres," Composites Science and Technology, vol. 63, no. 6, pp. 861-869, 2003.

[92] M. H. Ab Ghani and S. Ahmad, "The comparison of water absorption analysis between counterrotating and corotating twin-screw extruders with different antioxidants content in wood plastic composites," Advances in Materials Science and Engineering, vol. 2011, Article ID 406284, 4 pages, 2011.

[93] M. Mariatti, M. Jannah, A. A. Bakar, and H. P. S. A. Khalil, "Properties of banana and pandanus woven fabric reinforced unsaturated polyester composites," Journal of Composite Materials, vol. 42, no. 9, pp. 931-941, 2008.

[94] S. N. Monteiro, V. Calado, R. J. S. Rodriguez, and F. M. Margem, "Thermogravimetric behavior of natural fibers reinforced polymer composites-an overview," Materials Science and Engineering A, vol. 557, pp. 17-28, 2012.

[95] O. Hassan, T. P. Ling, M. Y. Maskat et al., "Optimization of pretreatments for the hydrolysis of oil palm empty fruit bunch fiber (EFBF) using enzyme mixtures," Biomass and Bioenergy, vol. 56, pp. 137-146, 2013.

[96] G. George, E. T. Jose, D. Åkesson, M. Skrifvars, E. R. Nagarajan, and K. Joseph, "Viscoelastic behaviour of novel commingled biocomposites based on polypropylene/jute yarns," Composites Part A: Applied Science and Manufacturing, vol. 43, no. 6, pp. 893-902, 2012.

[97] V. Fiore, T. Scalici, and A. Valenza, "Characterization of a new natural fiber from Arundo donax L. as potential reinforcement of polymer composites," Carbohydrate Polymers, vol. 106, no. 1, pp. 77-83, 2014.

[98] S. Shinoj, R. Visvanathan, and S. Panigrahi, "Towards industrial utilization of oil palm fibre: physical and dielectric characterization of linear low density polyethylene composites and comparison with other fibre sources," Biosystems Engineering, vol. 106, no. 4, pp. 378-388, 2010.

[99] E. Sassoni, S. Manzi, A. Motori, M. Montecchi, and M. Canti, "Novel sustainable hemp-based composites for application in the building industry: physical, thermal and mechanical characterization," Energy and Buildings, vol. 77, pp. 219-226, 2014.

[100] J. Holbery and D. Houston, "Natural-fiber-reinforced polymer composites in automotive applications," JOM, vol. 58, no. 11, pp. 80-86, 2006.

[101] S. H. Shuit, K. T. Tan, K. T. Lee, and A. H. Kamaruddin, "Oil palm biomass as a sustainable energy source: a Malaysian case study," Energy, vol. 34, no. 9, pp. 1225-1235, 2009.

[102] A. R. Kakroodi, Y. Kazemi, and D. Rodrigue, "Mechanical, rheological, morphological and water absorption properties of maleated polyethylene/hemp composites: effect of ground tire rubber addition," Composites Part B: Engineering, vol. 51, pp. 337-344, 2013.
[103] S. Kalia and B. S. Kaith, Cellulose Fibers: Bio- and Nano-Polymer Composites, Springer, 2011. 

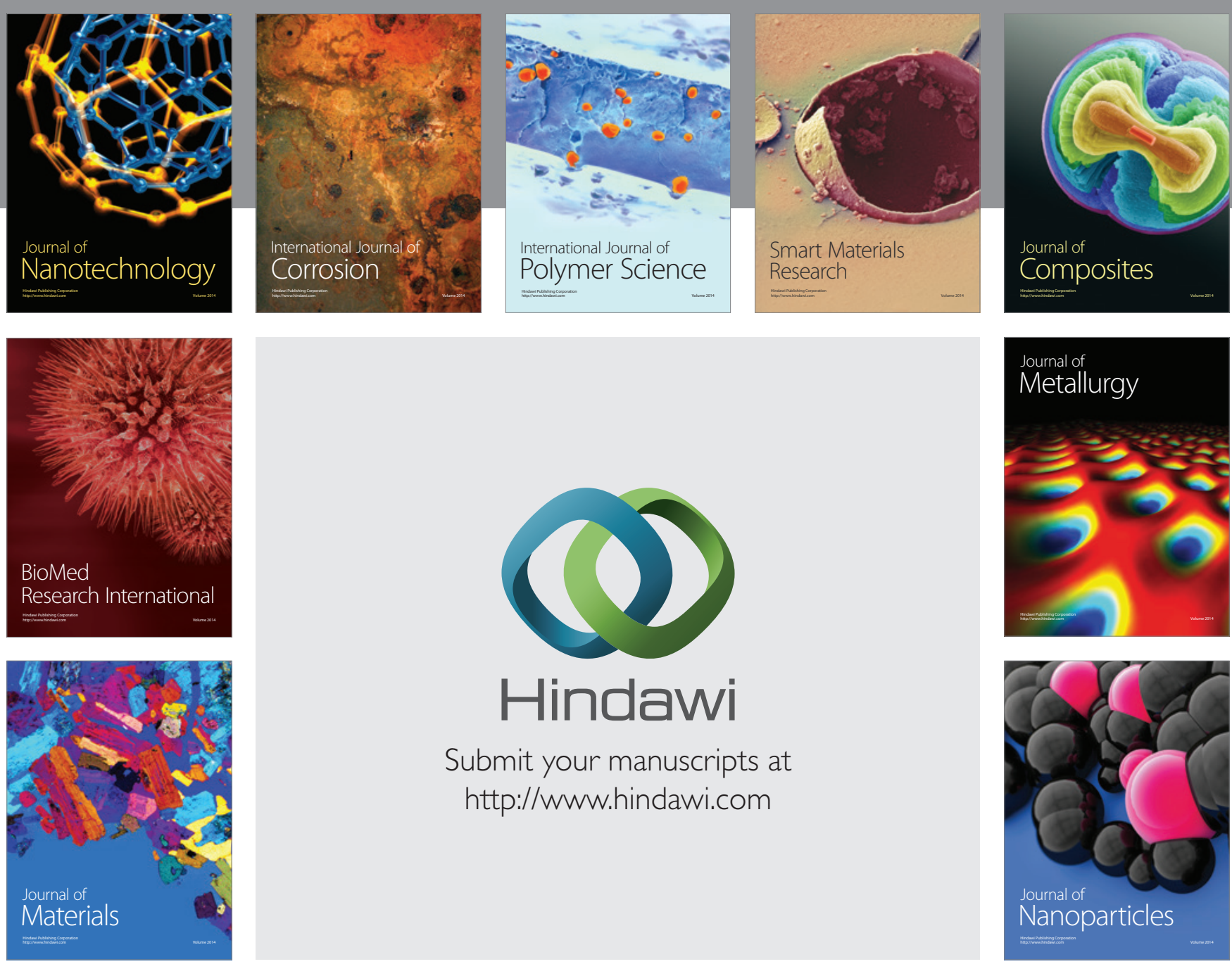

Submit your manuscripts at http://www.hindawi.com
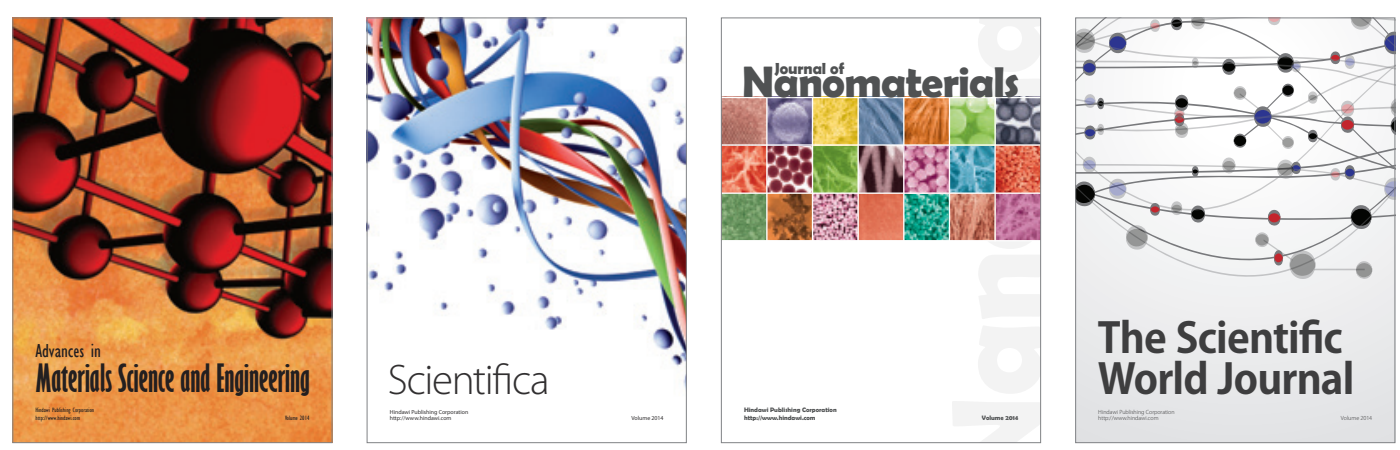

\section{The Scientific World Journal}
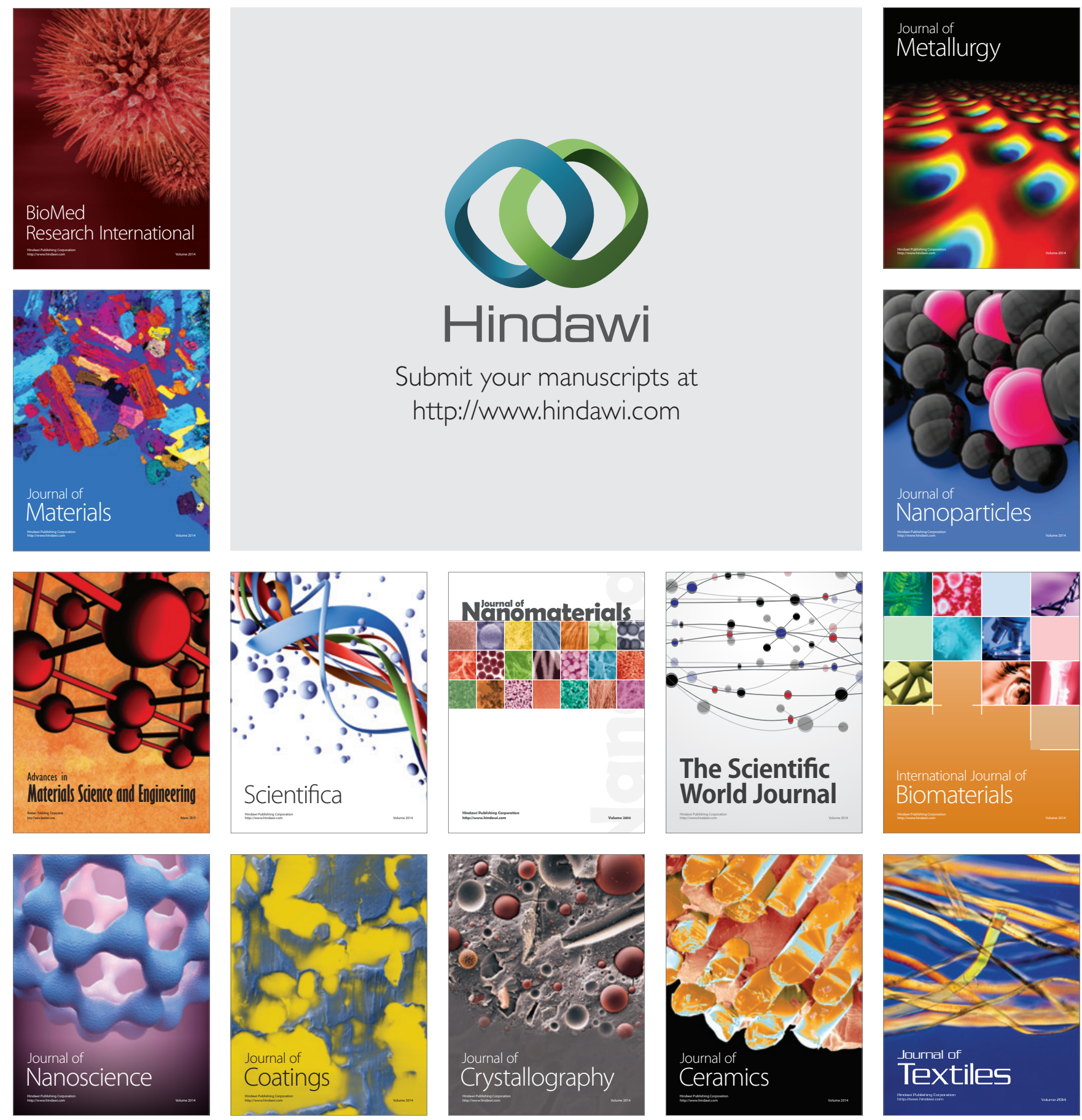